\title{
Teatro Aberto, quarenta anos de imagens
}

\author{
PAULA MAGALHÃES I FILIPE FIGUEIREDO
}

Reviver um passado de quatro décadas através da fotografia foi o desafio lançado ao encenador e fotógrafo João Lourenço, numa altura em que o Teatro Aberto assinala a importante efeméride. Quarenta anos passados sobre a estreia d'O Círculo de Giz Caucasiano, de Bertolt Brecht, espectáculo emblemático do então designado Grupo 4 (só em 1982 seria fundado o Novo Grupo), são as memórias afectivas das imagens, captadas pela câmara de quem também encena e dirige a companhia, que conduzem esta viagem no tempo.

Ao lado de fotografias do espectáculo inaugural de Brecht, autor recorrente na história do Grupo 4 e do Novo Grupo, tanto encontramos imagens de produções incontornáveis da companhia, cuja escolha foi determinada pela afectividade - Oiçam como Eu Respiro, de Dario Fo e Franca Rame (1982), Mãe Coragem e os Seus Filhos, de Bertolt Brecht (1986), Loucos por Amor, de Sam Shepard (1990), O Tempo e o Quarto, de Botho Strauss (1993), Peer Gynt, de Ibsen (2002), A Ópera de Três Vinténs (2005) ou O Senhor Puntila e o Seu Criado Mati (2010), de Brecht, entre outras -, como fotografias que se destacam pela sua potencial discursividade visual.

A imagem fotográfica apresentou-se desde sempre, para João Lourenço, como um objecto de grande fascínio, cuja prática desenvolveu desde a década de 1970. A memória desse tempo é ainda hoje capaz de evocar as relações de proximidade e o convívio com alguns dos principais agentes da fotografia, como os que giravam como satélites em torno da casa fotográfica Filmarte, dirigida por António Paixão, em cujas tertúlias se discutiam as novidades da fotografia. Em casa, conserva ainda as câmaras fotográficas desse tempo, como a Mamiya de película de médio formato e o ampliador Durst, que lhe abriam as portas aos mistérios da revelação fotográfica.

Assim, foi com naturalidade que o encenador passou a assumir também a figura do fotógrafo sempre presente e que em melhor posição se encontrava para captar a essência do espectáculo, satisfazendo as necessidades de produção e divulgação.

A par desta utilização das imagens, a fotografia sempre se apresentou para o encenador João Lourenço como um elemento do processo criativo, 
participando na construção do espectáculo. A sua passagem pelo Berliner Ensemble, em 1978, terá certamente inspirado um conjunto de práticas, nomeadamente o recurso à fotografia como instrumento de análise e de autoscopia do trabalho de criação durante os ensaios. Já na década de 1930, Brecht solicitava a presença do fotógrafo nos ensaios para captar imagens que seriam imediatamente reveladas e serviriam de instrumento de análise no ensaio seguinte. É ainda relevante a forma como Brecht utiliza a fotografia na fixação de modelos de encenação nos Modelbucher, de que o mais conhecido é o de Mãe Coragem e os Seus Filhos, em que a fotografia assume um estatuto de documento. É também essa dimensão documental da imagem fotográfica que João Lourenço põe em prática na constituição de uma memória visual e documental dos espectáculos do Teatro Aberto, privilegiando um olhar abrangente sobre a cena.

Dimensão igualmente presente nas imagens é o olhar sobre o trabalho do actor, que se manifesta na captação de movimentos e expressões importantes não só para o processo de criação da personagem, como também para o lugar que ocupa na cena.

Para lá do carácter eminentemente documental, a utilização da imagem técnica no espectáculo, através de projecções estáticas ou em movimento (fotografias, excertos de filmes, vídeo em directo, croma, etc.), assume-se desde cedo como uma forma de materializar as imagens mentais criadas pelo encenador a partir do texto. A utilização da imagem como estratégia de construção de uma poética de cena, se bem que já presente nos primeiros trabalhos como encenador, assume particular relevo em produções mais recentes como Hannah e Martin (2009), O Senhor Puntila e o Seu Criado Mati (2010), Purga (2011) ou Há Muitas Razões para Uma Pessoa Querer Ser Bonita (2012), evidenciando o lugar privilegiado da imagem no universo criativo do Teatro Aberto. 


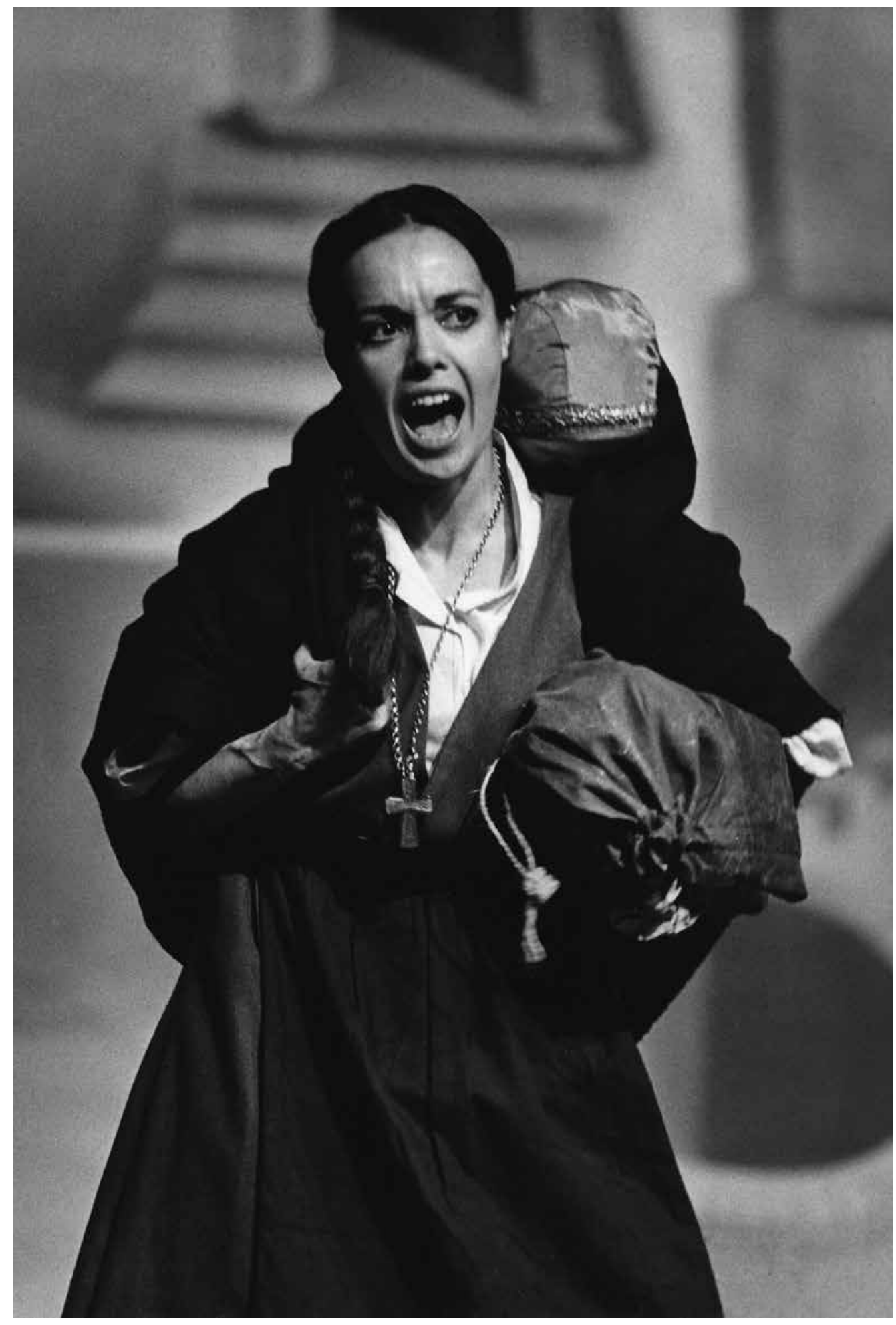



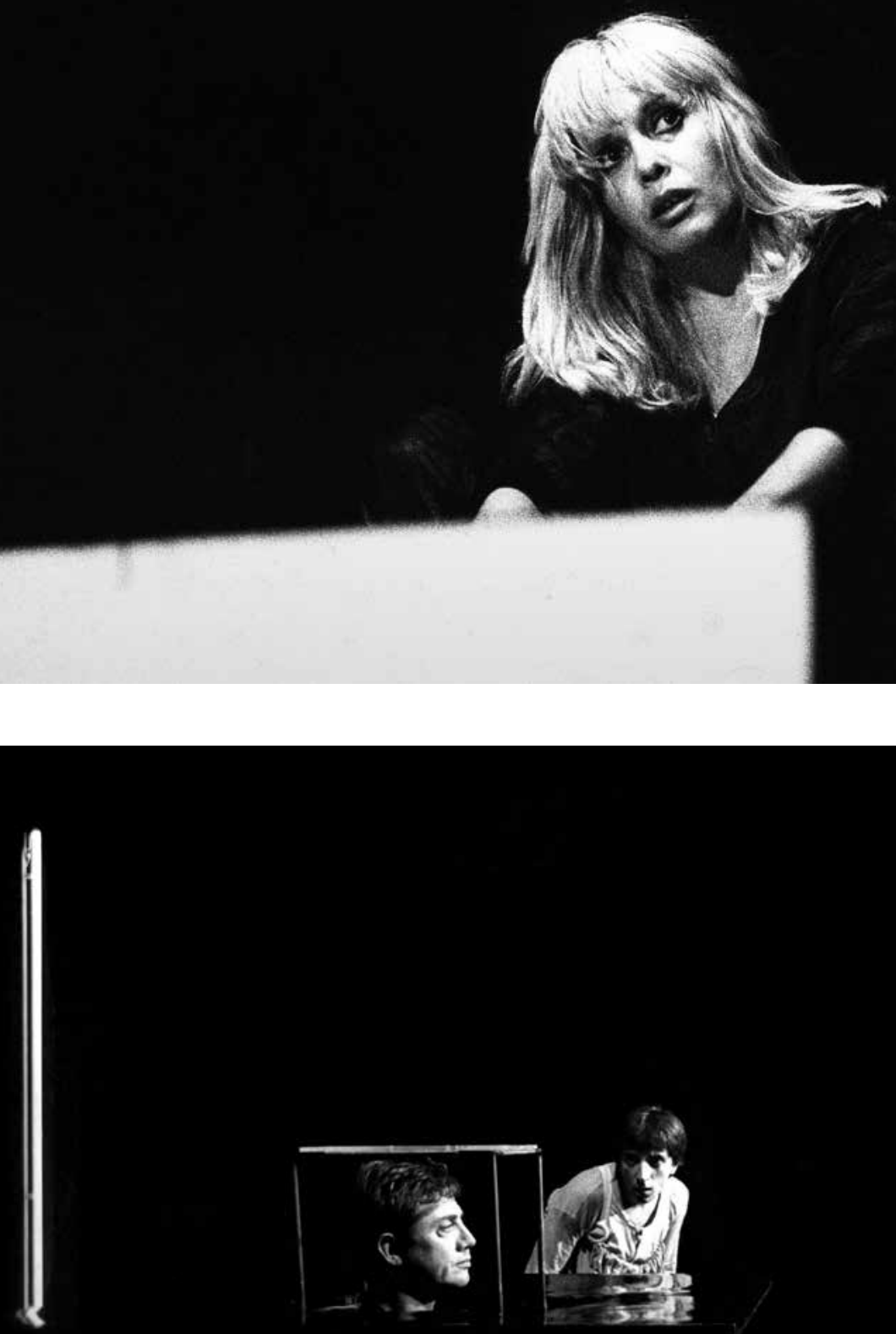


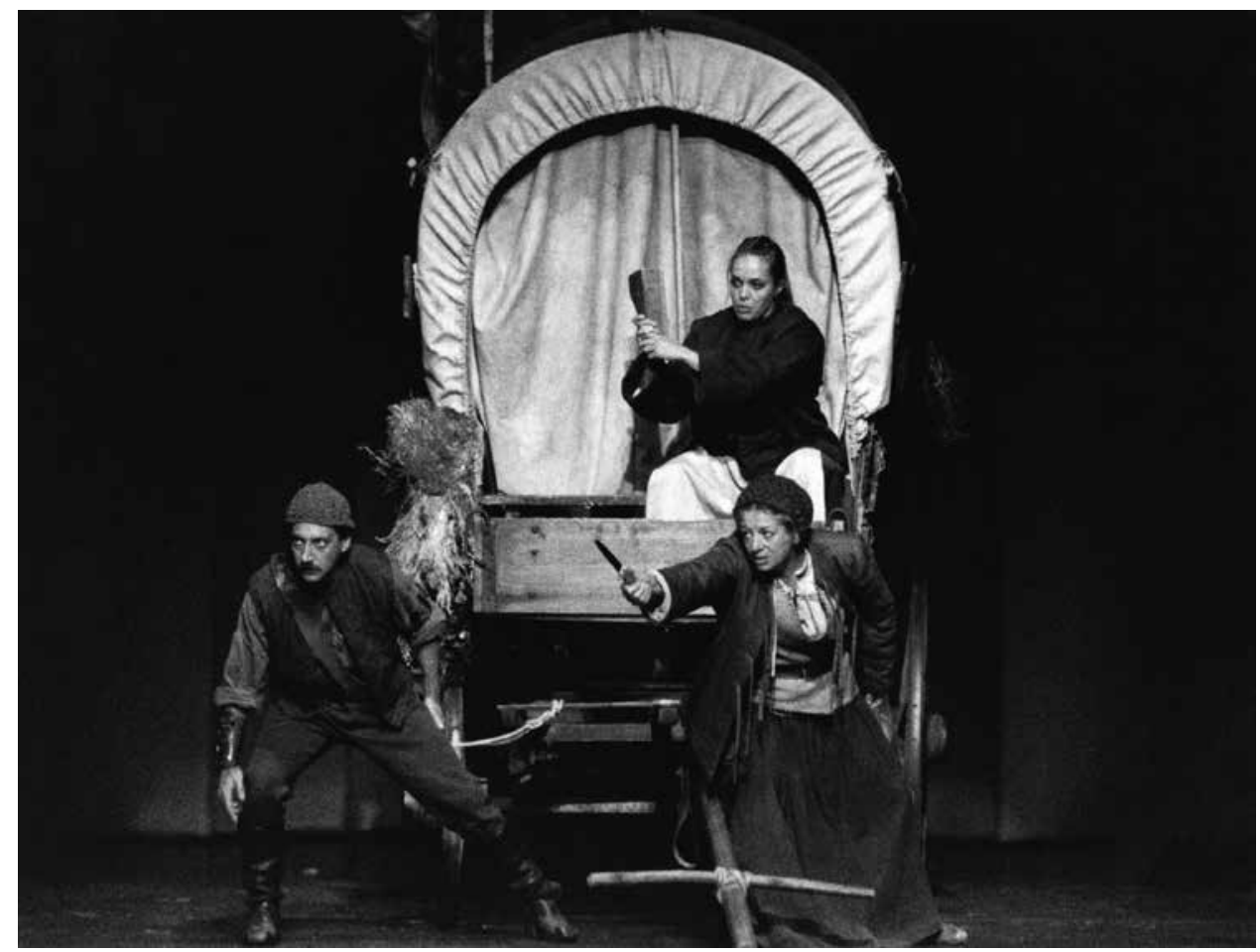

$$
8-0 .+
$$

an $\quad$ o 

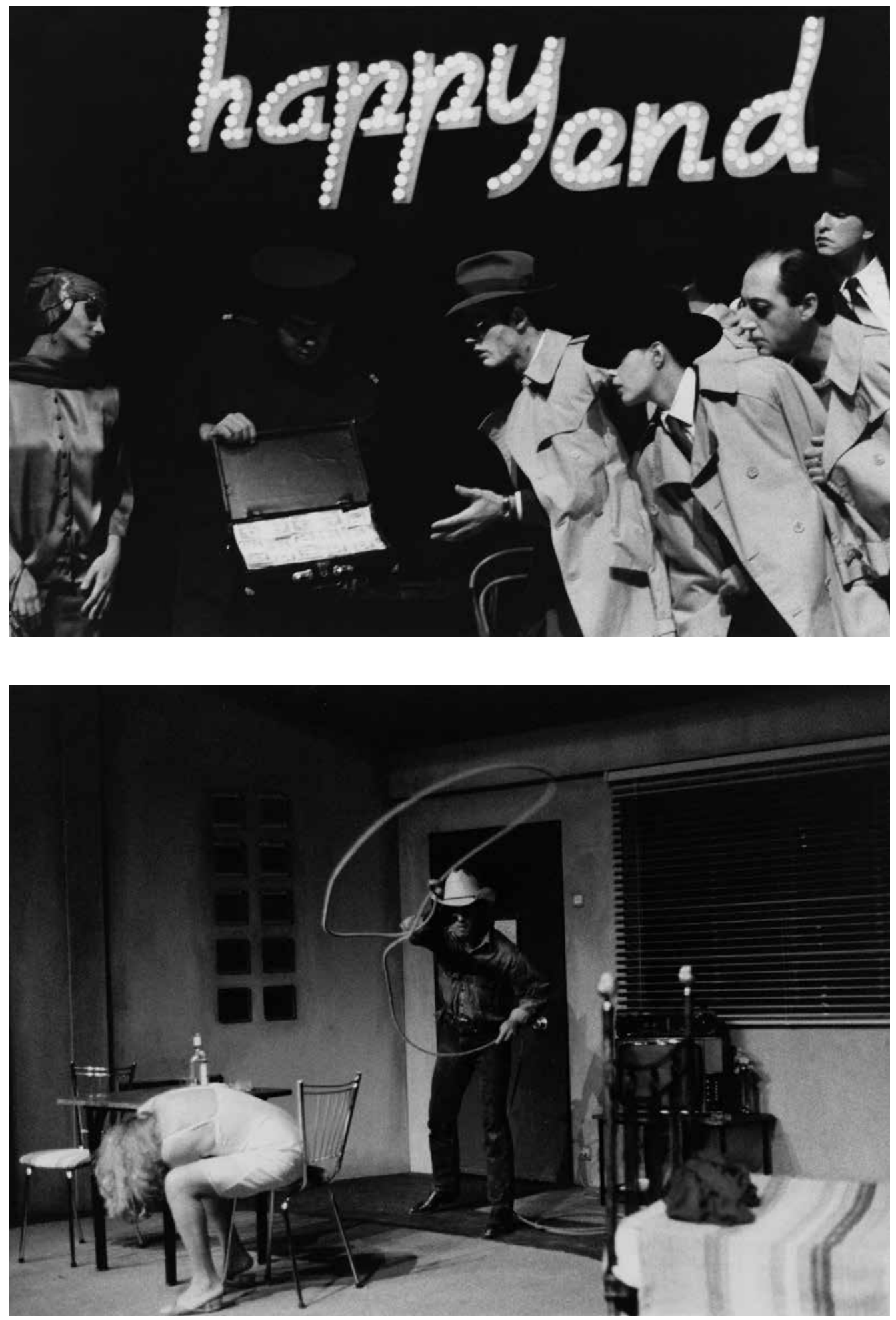

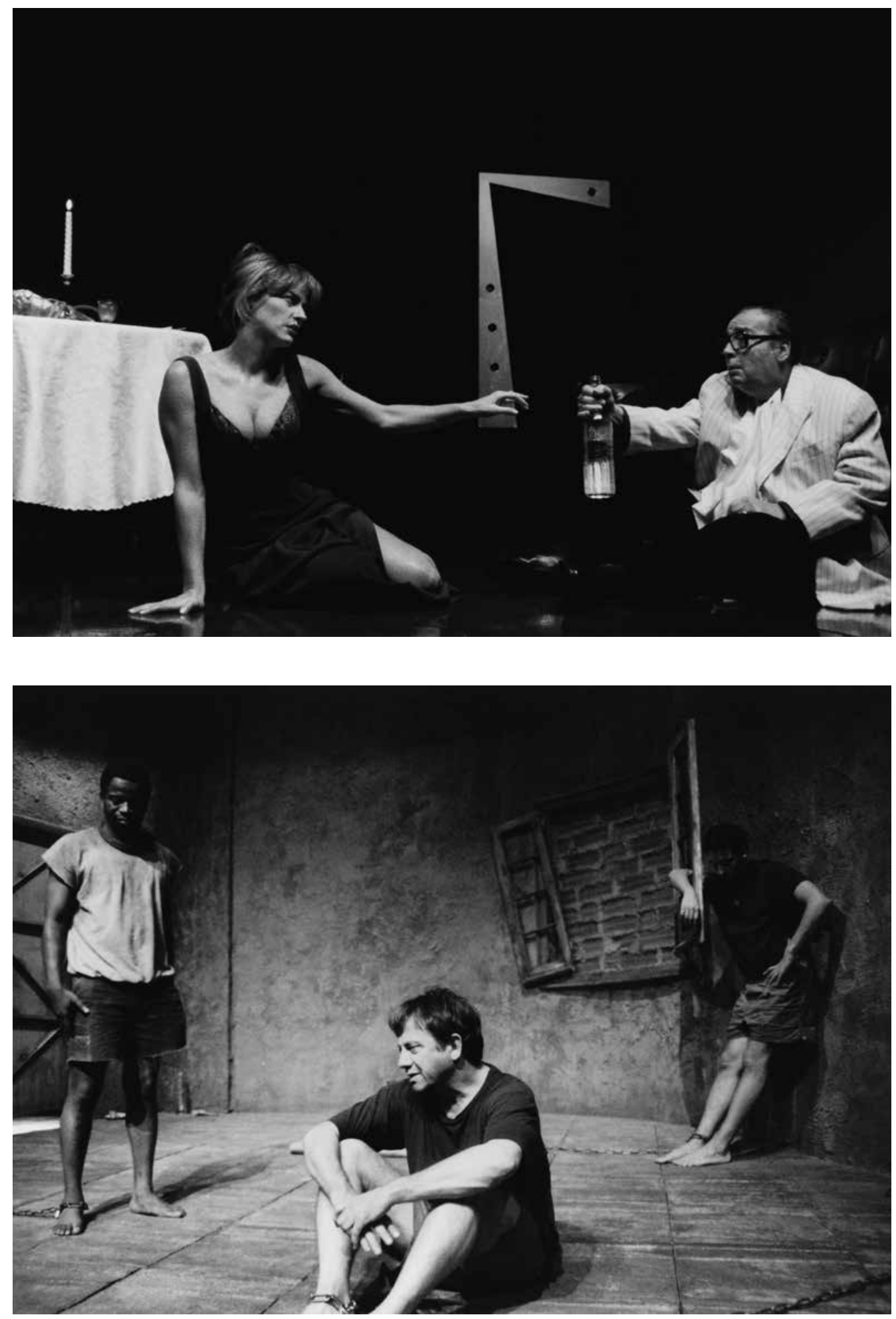

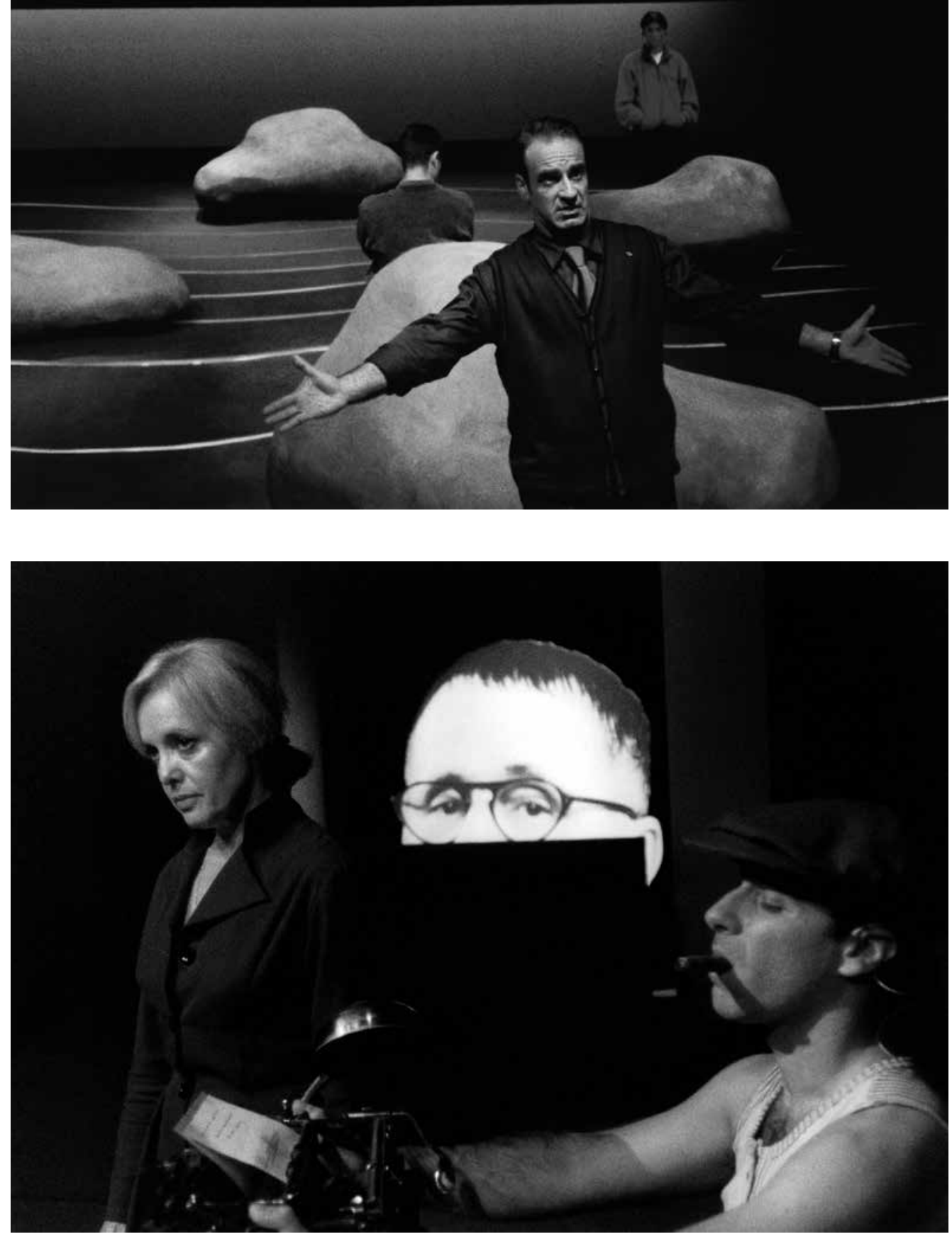

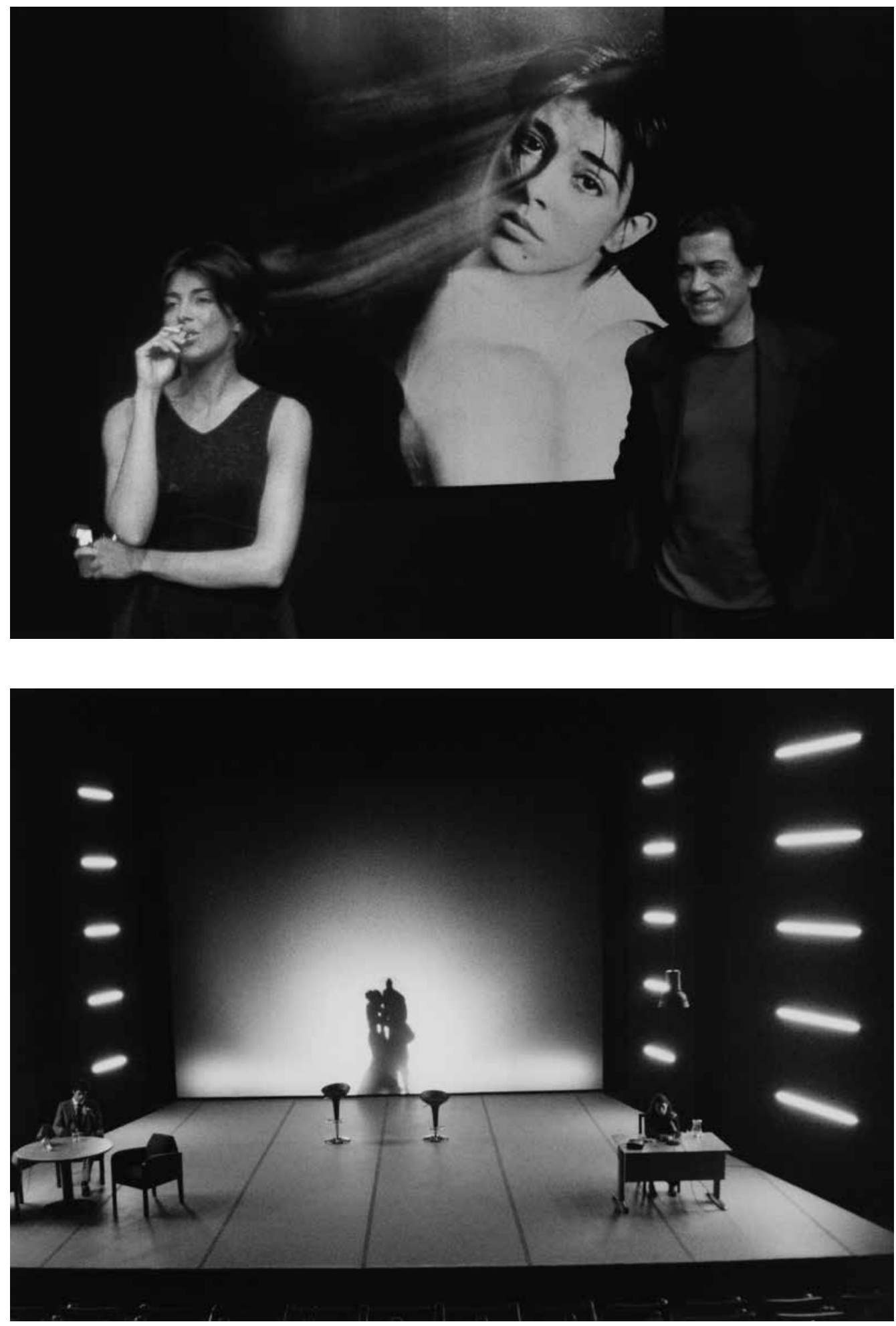


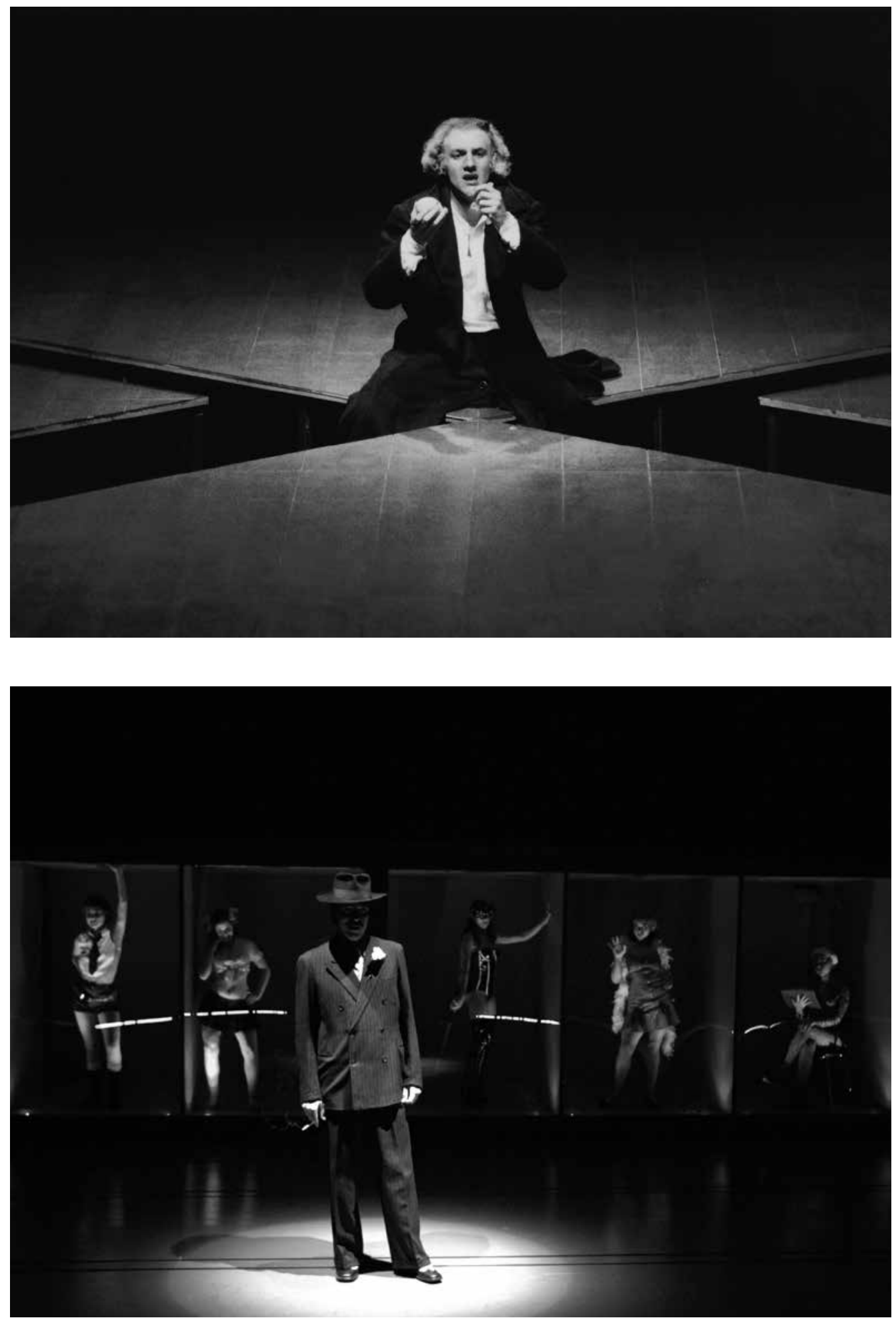



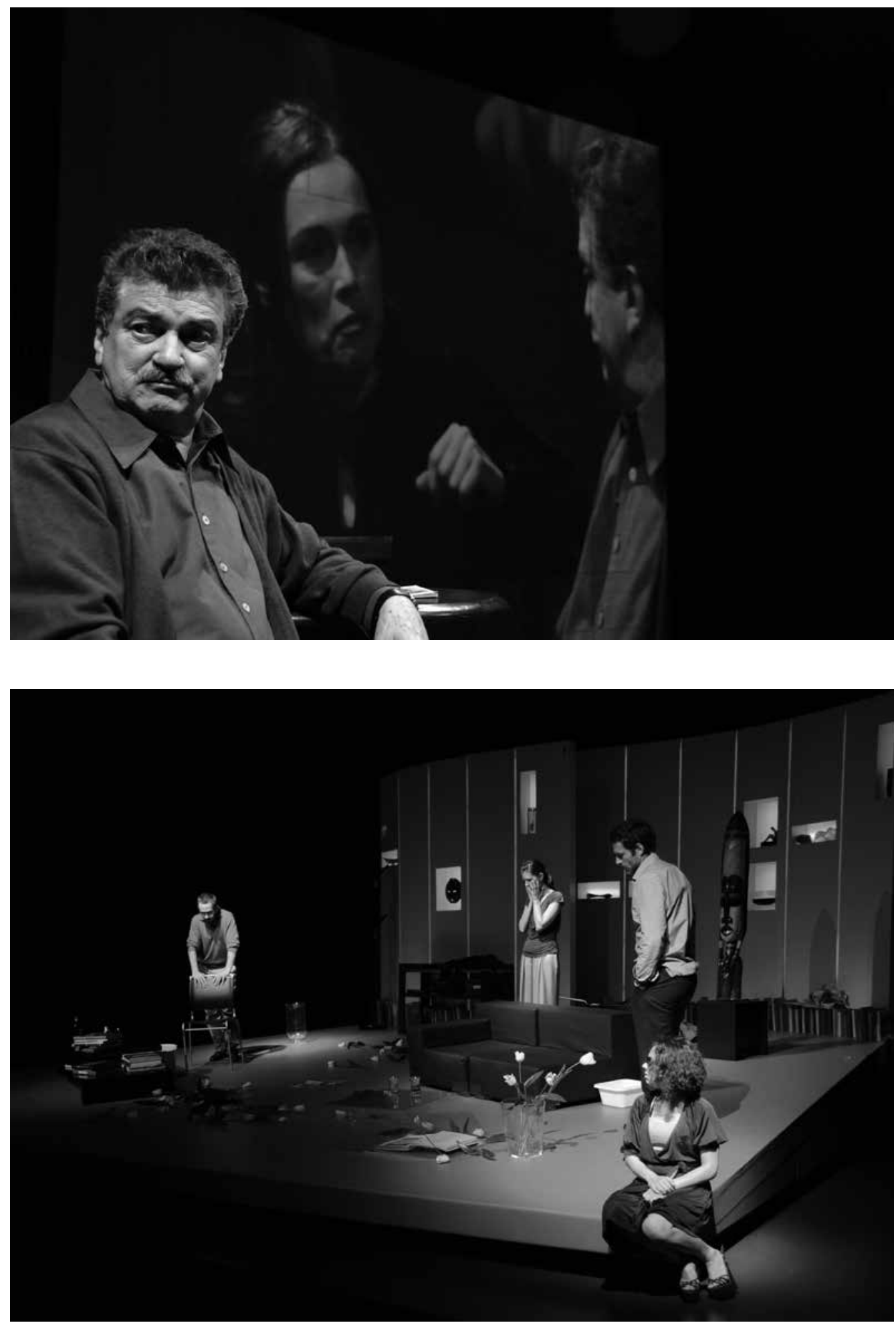

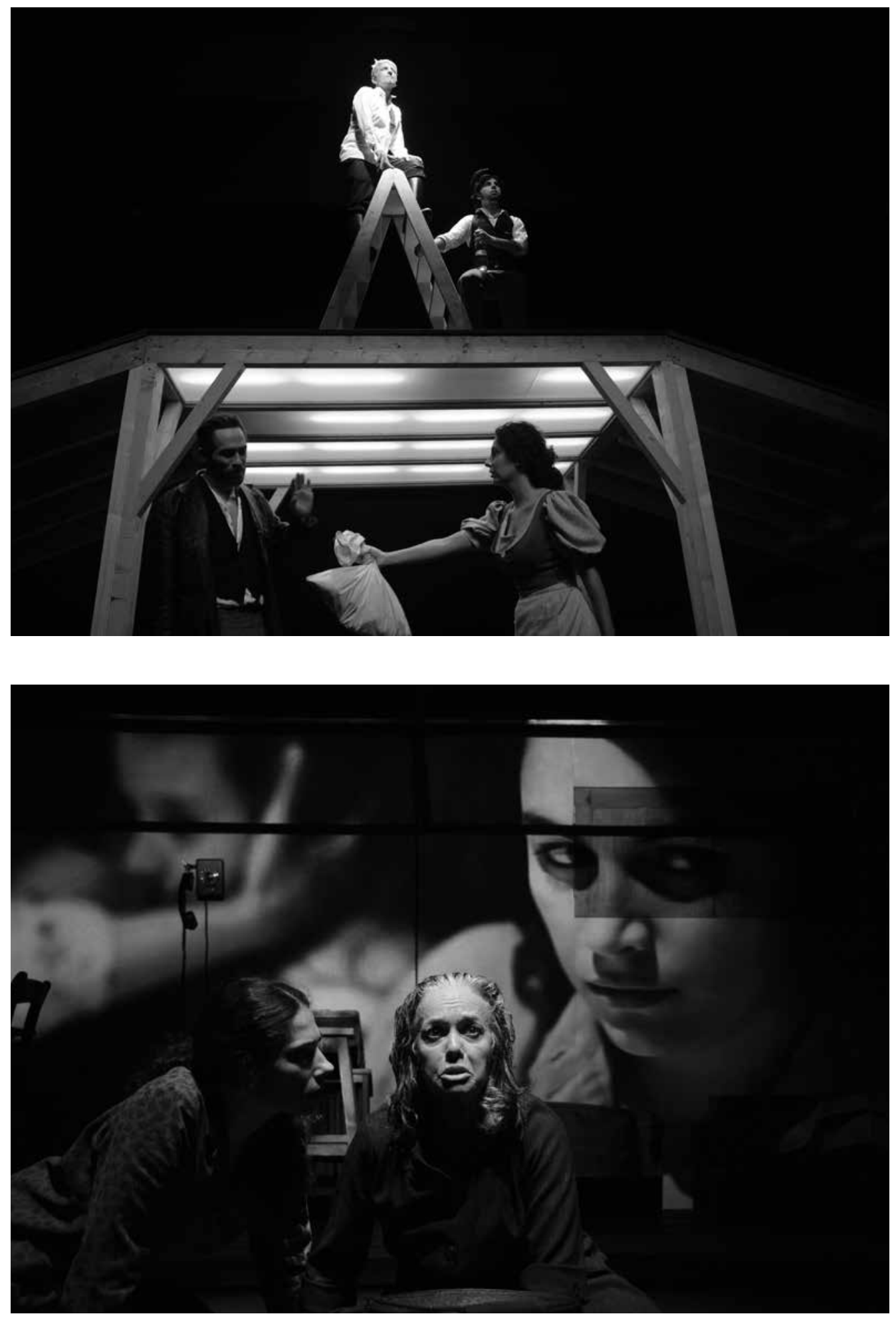

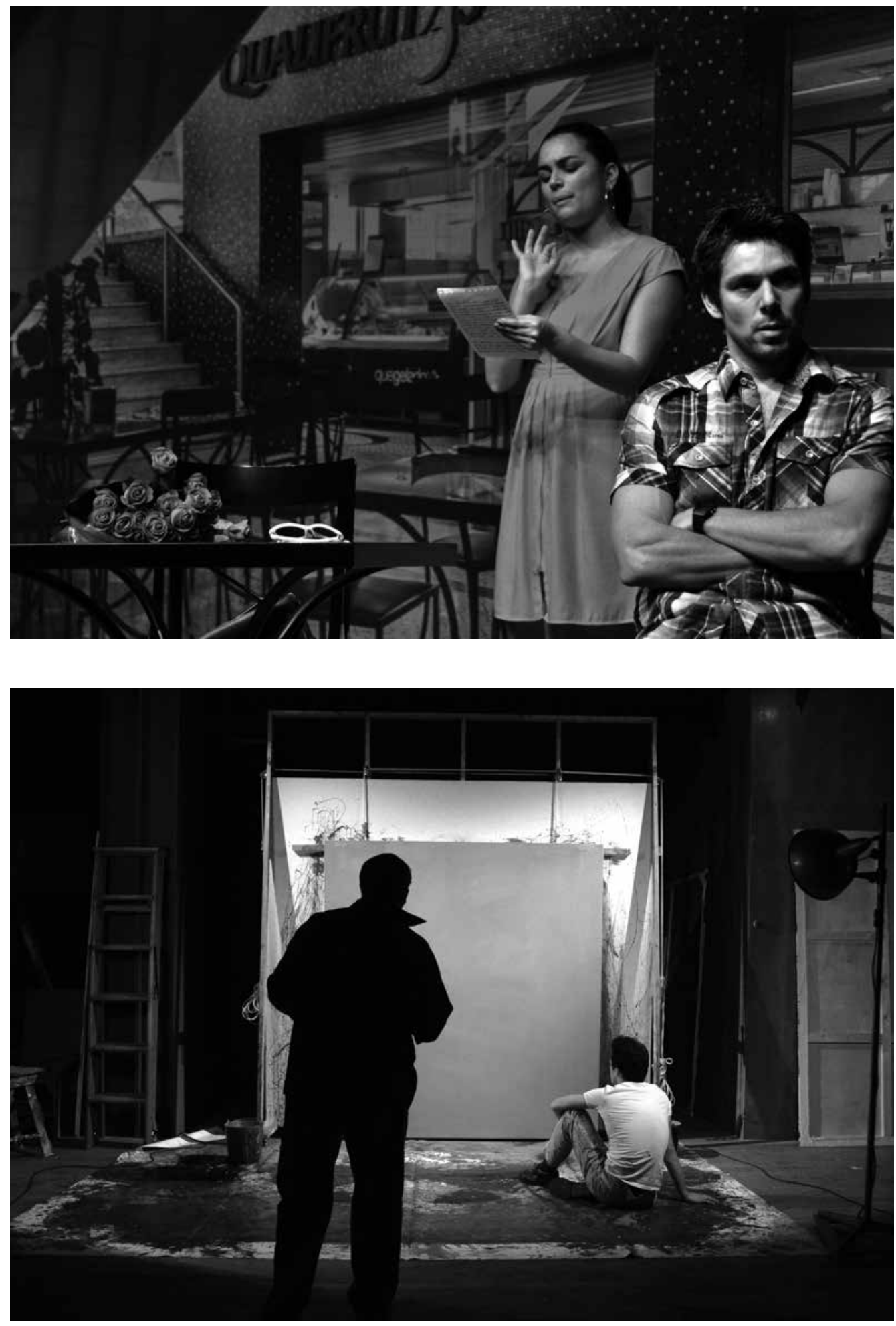


\section{ars}

$R=0$

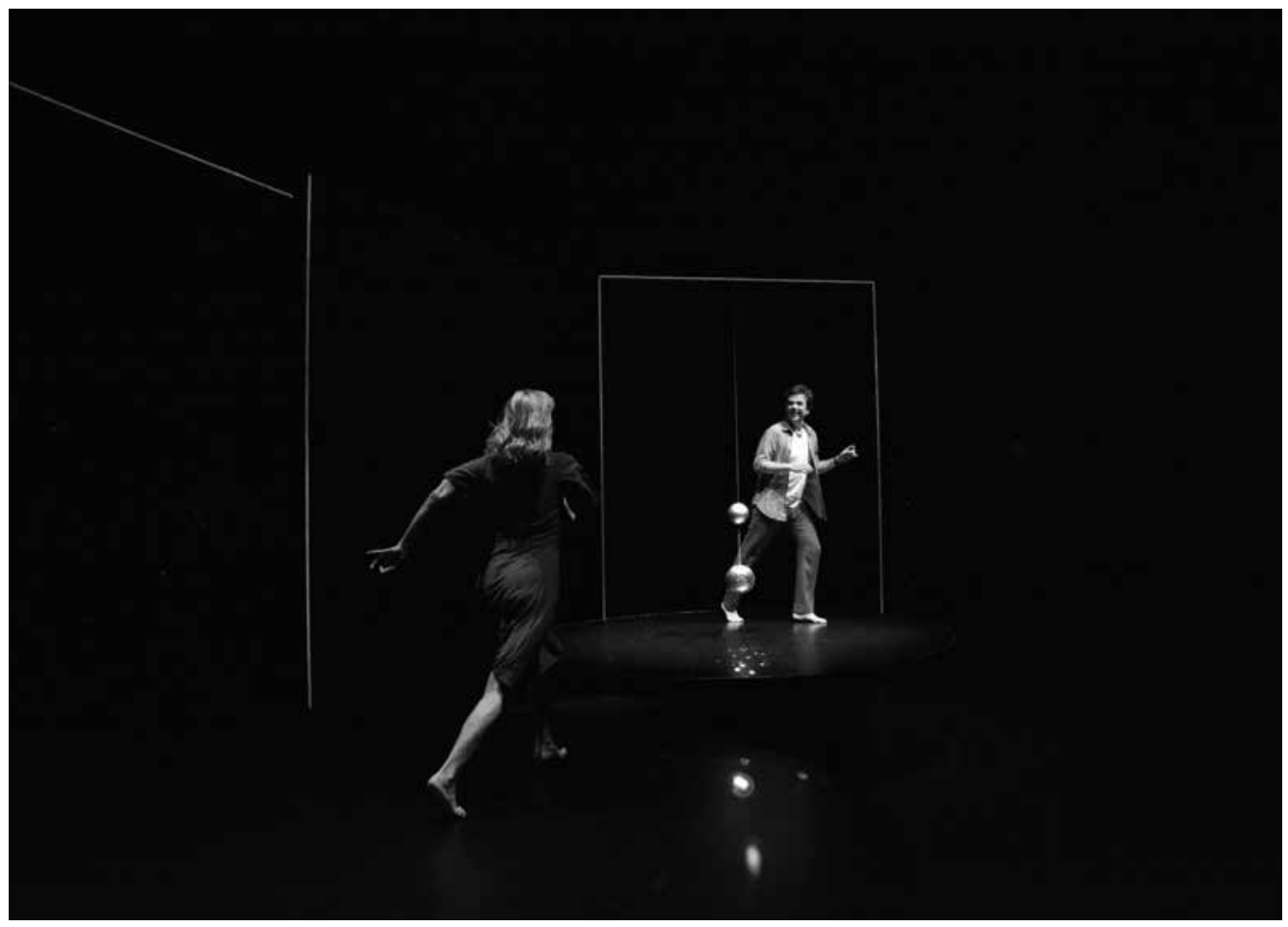




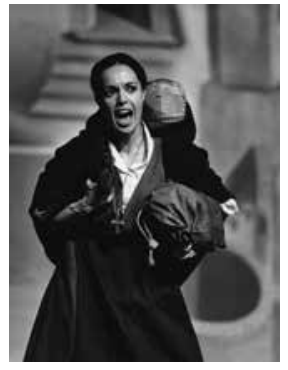

o Círculo de Giz Caucasiano, de Bertolt Brecht, enc. João Lourenço, Grupo 4, 1976 (Irene Cruz),

[F] João Lourenço

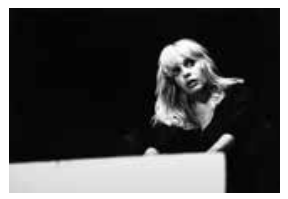

Oiçam como Eu

Respiro, de Dario Fo e Franca Rame, enc. João Lourenço, Novo Grupo, 1982 (Irene Cruz), [F] João

Lourenço

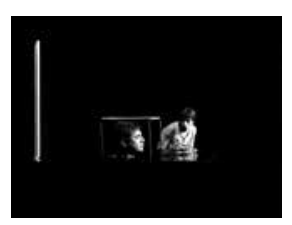

Tu e Eu, de Friedrich Karl Waechter, enc. João Lourenço, Novo Grupo, 1985 ( João Perry e Miguel Guilherme), [F] João Lourenço

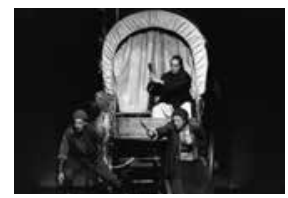

Mãe Coragem e os Seus Filhos, de Bertolt Brecht, enc. João Lourenço, Novo Grupo, 1986 (Francisco Pestana, Irene Cruz, Eunice Muñoz), [F] João Lourenço

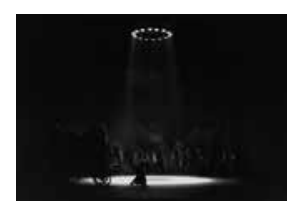

o Círculo de Giz Caucasiano, de Bertolt Brecht, enc. João Lourenço, Grupo 4, 1976 (Irene Cruz), [F] João Lourenço

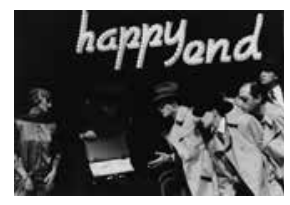

Happy End, de Bertolt Brecht / Dorothy Lane, enc. João Lourenço, Novo Grupo, 1989 (Isabel Ribas, Melim Teixeira, Paulo Oom, Cristina Carvalhal, Francisco Pestana, Fernando Luís), [F] João Lourenço

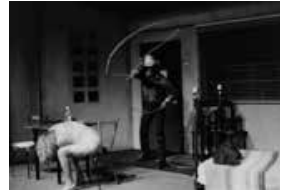

Loucos por Amor, de Sam Shepard, enc. João Lourenço, Novo Grupo, 1990 (Luísa Salgueiro, Virgílio Castelo), [F] João Lourenço

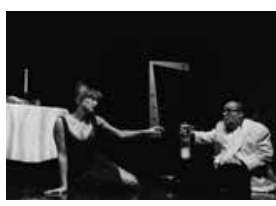

O Tempo e o Quarto, de Botho Strauss, enc. João Lourenço, Novo Grupo, 1993

(Alexandra Lencastre e Canto e Castrol,

[F] João Lourenço

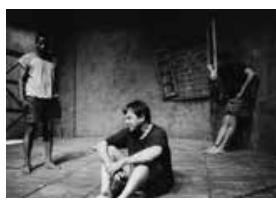

Alguém Olhará por Mim, de Frank McGuiness, enc. João Lourenço, Novo Grupo, 1994 (Orlando Sérgio, João Perrye Diogo Infante), [F] João Lourenço

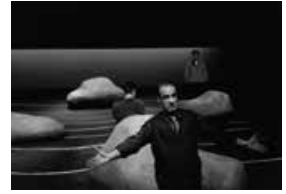

Água Salgada, de Conor McPherson, enc. João Lourenço, Novo Grupo, 1997 (José Jorge Duarte, Paulo Oom, Tobias Monteiro), [F] João Lourenço

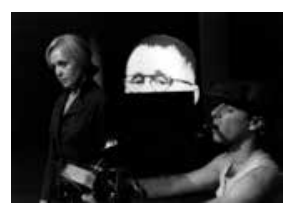

O Mar É Azul, Azul, de João Lourenço, José Fanha e Vera San Payo de Lemos, enc. João Lourenço, Novo Grupo, 1998 (Irene Cruz e José Jorge Duarte), [F] João Lourenço

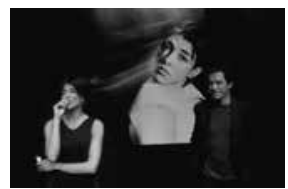

Quase, de Patrick Marber, enc. João Lourenço, Novo Grupo, 1999 (Catarina Furtado e Virgílio (astelo), [F] João Lourenço 


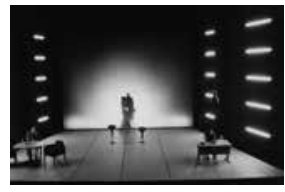

Socos, de Neil

LaBute, enc. João

Lourenço, Novo

Grupo, 2001 (Pedro

Lima, Anabela

Brígida, Phillippe

Leroux e Sofia de

Portugal), [F] João

Lourenço

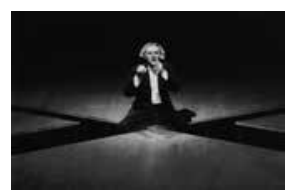

Peer Gynt, de Henrik Ibsen, enc. João

Lourenço, Novo

Grupo, 2002 (João

Pedro Vaz), [F] João

Lourenço

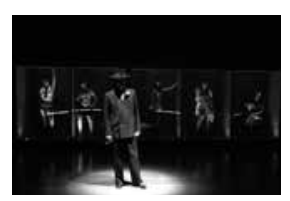

A Ópera de Três Vinténs, de Bertolt Brecht e Kurt Weill, enc. João Lourenço, Novo Grupo, 2005 (Mário Redondo e Adriana Aboim, Ana Sofia Santos, Vanda Elias, Joana Silva, Jennifer Veiga),

[F] João Lourenço

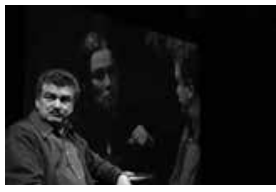

Hannah e Martin, de Kate Fodor, enc. João Lourenço, Novo Grupo, 2009 (Rui Mendes e Ana Padrão), [F] João Lourenço

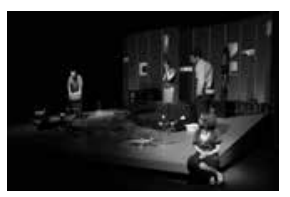

O Deus da Matança, de Yasmina Reza, enc. João Lourenço, Novo Grupo, 2009 (Sérgio Praia, Joana Seixas, Paulo Pires e Sofia de Portugal), [F] João Lourenço

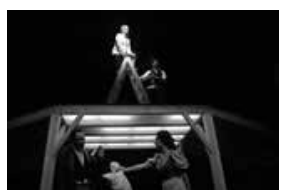

O Senhor Puntila e o Seu Criado Mati, de Bertolt Brecht, enc. João Lourenço, Novo Grupo, 2010 (Miguel Guilherme, Carlos Malvarez, Sérgio Praia, Cátia Ribeiro), [F] João Lourenço

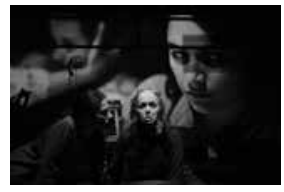

Purga, de Sofi Oksanen, enc. João Lourenço, Novo Grupo, 2011 (Patrícia André, Irene Cruz), [F] João Lourenço

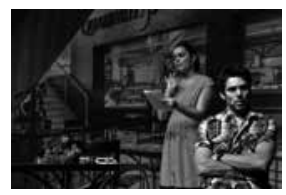

Há Muitas Razões para Uma Pessoa Querer Ser Bonita, de Neil Labute, enc. João Lourenço, Novo Grupo, 2012 (Ana Guiomar e Jorge Corrula), [F] João Lourenço

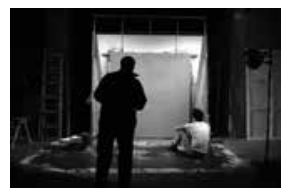

Vermelho, de John Logan, enc. João Lourenço, Novo Grupo, 2011 (António Fonseca e João Vicente), [F] João Lourenço

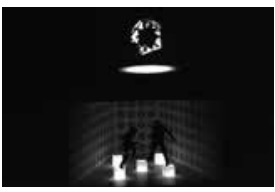

Amor e Informação, de Caryl Churchill, enc. João Lourenço, Novo Grupo, 2014 (João Vicente e Cristóvão Campos), [F] João Lourenço

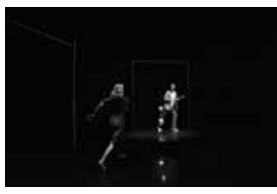

Constelações, de Nick Payne, enc. João Lourenço, Novo Grupo, 2016 (Joana Brandão e Pedro Laginha), [F] João Lourenço 